\title{
Os estados e o Sistema Único de Assistência Social: construção de capacidades estatais nos governos do Maranhão e de São Paulo
}

\author{
FABIANA TOCK ${ }^{1}$ \\ EDUARDO JOSÉ GRIN ${ }^{1}$ \\ LAURO GONZALEZ ${ }^{2}$
}

\author{
${ }^{1}$ Fundação Getulio Vargas (FGV EAESP) / Escola de AdMINISTRAÇÃo de EMPRESAS, SÃo PaUlo - SP, BraSiL \\ 2 Fundação Getulio Vargas (FGVcemif) / Centro de Estudos em MicrofinançAS E InClusÃo Financeira, SÃo PAULO - SP, BRASIL
}

\begin{abstract}
Resumo
Este artigo se insere no conjunto de estudos que buscam compreender as implicações do desenho federativo nas políticas públicas, adotando como unidade de análise os sistemas nacionais de políticas públicas. Emerge dos diversos estudos a importância do fortalecimento gradativo e continuado das capacidades estatais dos governos subnacionais para implementar políticas. Diversos trabalhos investigam a relação entre os sistemas federalizados e o desenvolvimento de capacidades estatais nos governos locais, entretanto, pouco se sabe como ocorre essa relação nos governos estaduais. Esta pesquisa investigou como o Sistema Único de Assistência Social (SUAS) afeta as capacidades dos governos estaduais de implementar políticas. Com este fim, analisou o Programa de Erradicação do Trabalho Infantil (PETI) nos estados do Maranhão e de São Paulo. Buscou-se explicar como a combinação entre as características institucionais do SUAS e as condições estruturais, institucionais e políticas presentes nestes estados regulou ou possibilitou a criação de capacidades estatais. Os resultados apontam que tais condições foram determinantes na construção de capacidades e, sobretudo, informam a respeito do papel assumido pelo governo do estado no SUAS.
\end{abstract}

Palavras-chave: Federalismo. Sistema Único de Assistência Social. Capacidades estatais. Governos estaduais.

\section{The Brazilian states and the Federal Social Assistance System: state capacity-building in Maranhão and São Paulo}

\begin{abstract}
This article is part of a set of studies seeking to understand the implications of federative design in public policies. The unit of analysis adopted is the national public policies systems. The studies suggest the importance of gradual and continued strengthening of state capacities of subnational governments to implement policies. Several articles investigate the relationship between federalized systems and state capacity-building in local governments. However, little is known about how this relationship occurs in state governments. This research investigated how the Brazilian Sistema Único de Assistência Social (SUAS) (Federal Social Assistance System) affects the capacity of state governments to implement policies and analyzed the program of eradication of child labor in the states of Maranhão and São Paulo. We sought to explain how the combination of SUAS institutional characteristics and the structural, institutional, and political conditions present in these states have regulated or built state capacities. The results indicate that these conditions were decisive for state capacity-building and, above all, show the role played by the Brazilian state governments in SUAS.
\end{abstract}

Keywords: Federalism. Sistema Único de Assistência Social. State capacity-building. State governments.

\section{Los estados y el Sistema Unificado de Asistencia Social: creación de capacidad estatal en los gobiernos de Maranhão y São Paulo}

\section{Resumen}

Este artículo es parte del conjunto de estudios que busca comprender las implicaciones del diseño federativo en las políticas públicas y adopta como unidad de análisis los sistemas nacionales de políticas públicas. De los diversos estudios surge la importancia del fortalecimiento gradual y continuo de las capacidades estatales de los gobiernos subnacionales para implementar políticas. Varios estudios investigan la relación entre los sistemas federalizados y el desarrollo de la capacidad estatal en los gobiernos locales, sin embargo, se sabe poco acerca de cómo se produce esta relación en los gobiernos de los estados. Esta investigación averiguó cómo el Sistema Unificado de Asistencia Social (SUAS) afecta las capacidades de los gobiernos estatales para implementar políticas y, con este fin, analizó el Programa para la Erradicación del Trabajo Infantil en los estados de Maranhão y São Paulo. Se intentó explicar cómo la combinación de las características institucionales del SUAS y las condiciones estructurales, institucionales y políticas presentes en estos estados o reguló o posibilitó la creación de capacidades estatales. Los resultados indican que estas condiciones fueron cruciales en la creación de capacidades y, sobre todo, informan acerca del rol asumido por los gobiernos de los estados en el SUAS.

Palabras clave: Federalismo. Sistema Único de Assistência Social. Capacidades estatales. Gobiernos estatales. 


\section{INTRODUÇÃO}

Sabe-se que o federalismo tem implicações nas políticas públicas. No Brasil, para compreender esta relação é preciso analisar os aspectos que estruturaram a descentralização em curso desde 1988 e que afetam as capacidades dos governos subnacionais de implementar uma política. A literatura que estuda o tema apoia-se em dois argumentos complementares: a) o papel preponderante assumido pelo governo federal na regulação das políticas sociais de forma a garantir resultados mais homogêneos na sua implementação por entes autônomos (ARRETCHE, 1996; BICHIR, 2011, 2016a; LICIO, 2012); b) a relação positiva entre a engenharia institucional dos sistemas nacionais de políticas públicas e o desenvolvimento das capacidades estatais nos níveis subnacionais de governo (BICHIR, 2011, 2016a; FRANZESE e ABRUCIO, 2013; GRIN, 2016).

Este artigo busca investigar como os sistemas nacionais afetam as capacidades estatais dos governos estaduais de implementar políticas. Para este fim, no âmbito do Sistema Único de Assistência Social (SUAS), será analisada a construção de capacidades estatais no Programa de Erradicação do Trabalho Infantil (PETI) nos estados do Maranhão e de São Paulo.

Com a promulgação da Constituição de 1988, um novo arranjo federativo tomou corpo no Brasil: a autonomia política, administrativa e financeira dos municípios e a redistribuição de recursos do nível federal às esferas subnacionais trouxeram importantes consequências à conformação de um novo arranjo institucional no campo das políticas públicas. De forma central, reforçou-se o papel indutivo do governo federal, visando incentivar os governos a aderirem às políticas nacionais para lidar com a baixa capacidade institucional e administrativa dos entes subnacionais.

Os sistemas nacionais de políticas públicas alinhados a essa visão instituíram novos arranjos de gestão objetivando qualificar a cooperação federativa. Um impacto importante da lógica dos sistemas nacionais é o fortalecimento gradativo e continuado das capacidades estatais dos níveis subnacionais de governo (BICHIR, 2011, 2016a; FRANZESE e ABRUCIO, 2013). Ao transferir recursos vinculados aos programas e grande parte da gestão a esses níveis de governo, os sistemas criaram condições para o surgimento de uma burocracia local favorecendo o fortalecimento subnacional (FRANZESE e ABRUCIO, 2013).

Quanto ao SUAS, para além do reconhecimento de que as regras constitucionais delegaram aos governos estaduais um papel complementar e residual, pouco se sabe "[...] sobre quem implementa a política de assistência social no estado, como a política é implementada, assim como os recursos estaduais nela investidos" (SOUZA, 2018, p. 271). Os trabalhos de Silva (2015), Pereira (2016) e Souza (2018) são contribuições importantes para elucidar as capacidades estatais dos governos estaduais de implementar a política nacional de assistência social. Por meio de categorias analíticas distintas, os resultados apontam a existência de uma elevada heterogeneidade nas capacidades estatais dos estados no âmbito do SUAS. Esta constatação, por sua vez, relativiza a ideia de que os sistemas nacionais produzem efeitos homogêneos nos entes subnacionais (SILVA, 2015). Assim, o que pode explicar as diferenças quanto às heterogeneidades encontradas e as variações nas capacidades estatais nos estados brasileiros?

Esta pesquisa buscou analisar diferentes variáveis existentes nos estados que, combinadas com as regras, processos e mecanismos institucionais do SUAS, viabilizaram a criação de capacidades estatais. A investigação buscou examinar em que medida este processo influenciou a produção heterogênea de capacidades do SUAS nos estados. $O$ artigo está dividido em três seções, além desta introdução e da conclusão. A primeira apresenta o campo de estudo das capacidades estatais. A segunda, a metodologia adotada, e a terceira, os resultados da análise das capacidades estatais construídas mediante recorte temático e espacial e os fatores que contribuíram para a construção ou regulação destas.

\section{Sistemas Nacionais de Políticas Públicas e a Construção de Capacidades Estatais}

Os sistemas de políticas públicas têm sido estudados como um importante recurso para coordenar as diferentes atribuições das três esferas de governo no federalismo descentralizado encetado no Brasil após 1988. O resultado foi ampliar e melhorar a oferta e provisão de programas e serviços e gerar convergência às diretrizes nacionais. Assim, os sistemas respondem ao duplo desafio de implementação de uma agenda nacional de universalização de políticas sociais, bem como de resolução dos dilemas das atribuições comuns do artigo 23 da Constituição Federal de 1988 (FRANZESE, 2010). 
No entanto, os sistemas dependem de estruturas de incentivos à adesão, pois a decisão dos entes subnacionais de se enquadrarem às normas federais é decisiva para o seu êxito. No contexto pós-constituinte, a baixa capacidade estatal subnacional reforçou a necessidade da construção de estratégias federais de indução, visando incentivar sua adesão e garantir padrões mínimos de implementação da política (ARRETCHE, 1999; BICHIR, 2014, 2016a; LICIO, 2012). Todavia, não se previu o desenvolvimento de capacidades estatais subnacionais, cuja ausência se intensificou com a descentralização ao largo dos anos, levando-as gradualmente a serem inseridas no bojo das iniciativas de cooperação federativa.

Desse modo, um impacto importante da lógica dos sistemas de políticas públicas é o fortalecimento gradativo e continuado das capacidades estatais das esferas subnacionais (ABRUCIO, FRANZESE e SANO, 2013; BICHIR, 2016a; FRANZESE e ABRUCIO, 2013; GRIN e ABRUCIO, 2018). Isto porque a implementação de políticas em escala nacional requer a capacidade de coordenação da União, mas depende, sobretudo, das capacidades institucionais dos governos locais para enfrentar as exigências da municipalização (BICHIR, 2011). A qualidade da provisão do serviço e o resultado da política dependeriam de mecanismos que buscassem desenvolver a gestão local para garantir o compliance às regras e padrões mínimos de implementação.

Com vistas a esse desafio, além de vincular os recursos à efetiva oferta dos serviços, os sistemas de políticas públicas condicionaram os repasses à existência de conselhos, fundos compartilhados e planos setoriais nos governos subnacionais. Ao transferir não somente recursos vinculados aos programas, mas grande parte da gestão para esses níveis de governo, criaram-se condições para o surgimento e fortalecimento de uma burocracia local (FRANZESE e ABRUCIO, 2013). Assim, é razoável assumir que os arranjos dos sistemas de políticas públicas operam sobre um arcabouço de medidas e normativas cujo objetivo também é o desenvolvimento das capacidades estatais em nível subnacional (BICHIR, 2011, 2016a; GRIN e ABRUCIO, 2018).

Na literatura, o conceito de capacidades estatais é utilizado como estratégia analítica para compreender os diferentes resultados políticos do Estado, ainda que carregue uma pluralidade de significados, meios de verificação e propósitos na sua aplicação. Os maiores esforços em precisar o significado do termo encontram-se nos estudos de abordagem estadocêntrica do final dos anos 70, que passaram a pensar o Estado não como um espaço de acomodação dos interesses de grupos sociais, mas como um ator capaz de formular e perseguir objetivos próprios. A obra seminal Bringing the State Back In (1985) aborda os mecanismos e os regimentos que conferem poder de agência e capacidade de ação autônoma ao Estado.

Os autores filiados a esta corrente (EVANS, 1993, 2003; EVANS e RAUSCH, 2014; GEDDES, 1994; SKOCPOL, 1985) retomaram a perspectiva weberiana, argumentando que a ação do Estado pode ser explicada em termos de suas características constitutivas, conhecendo-se as estruturas organizacionais que influenciam o seu poder de agência. Desta perspectiva, o conceito de capacidades estatais está relacionado à autonomia dos governos e aos recursos que possuem para implementar suas políticas (SKOCPOL, 1985). Nesse sentido, serve como variável explicativa da eficiência e eficácia para alcançar seus objetivos.

A visão estadocêntrica apoia-se na noção weberiana de burocracia, compreendendo-a como uma estrutura racionalmente organizada que tem por base preferências e interesses endógenos aos burocratas. Não por acaso, este é o ponto de partida para os diversos estudos que buscaram comprovar os efeitos das capacidades estatais no desenvolvimento econômico e social.

A virada do século impulsionou novos focos analíticos sobre os arranjos políticos internos como determinantes da capacidade de ação dos governos. No entanto, mantém-se usual na literatura a relevância sobre as capacidades de ação governamental para implementar suas políticas. Embora haja algum consenso sobre esse tratamento teórico, a definição das dimensões constitutivas e de possíveis variáveis operativas deste conceito é bem menos consensual (BOWMAN e KEARNEY, 1988; CINGOLANI, 2013; GOMIDE, PEREIRA e MACHADO, 2018; GRIN, 2012).

É diversa a disseminação de estudos empíricos que mobilizam as capacidades estatais em diferentes áreas de políticas. Alguns autores sugerem que, justamente pelo fato de o contexto democrático requerer a ampliação das capacidades de articulação e interlocução do Estado, é ainda mais imprescindível o desenvolvimento das capacidades técnico-administrativas (GRIN, 2012, 2016; KJAER, HANSEN e THOMSEN, 2002; SKOCPOL e FINEGOLD, 1982). Nessa linha, no caso brasileiro, o foco privilegiado da literatura tem sido as capacidades administrativo-burocráticas.

A abordagem estadocêntrica de capacidades estatais (CINGOLANI, 2013) destaca a importância da capacidade organizacional e das burocracias weberianas profissionais compostas por funcionários recrutados de acordo com critérios meritocráticos 
(EVANS e RAUSCH, 2014; GEDDES, 1994; OLSEN, 2006; SIKKINK, 1991; SKOWRONEK, 1984). Dessa maneira, o Estado pode atingir suas metas se for dotado de recursos chave, como servidores qualificados e recursos financeiros, para expandir a eficácia da sua ação na sociedade (SKOCPOL, 2002). Assim, uma maneira de investigar as capacidades estatais é identificar estruturas organizacionais cuja ausência, ou presença, seja fundamental para os governos realizarem suas tarefas (EVANS, RUESCHMEYER e SKCOPOL, 2002).

Desenvolver capacidades significa aumentar a eficiência e a capacidade de resposta do governo, o que requer o reforço de atributos de competência gerencial, técnica e administrativa. A implementação de políticas apoia-se no desenvolvimento dessas capacidades, ou seja, no fortalecimento da infraestrutura institucional (GRINDLE, 1997; SIKKINK e WOLF, 1993). Por esse motivo, um dos eixos básicos das abordagens estadocêntricas é que estruturas estatais podem constituir variáveis explicativas válidas para analisar os resultados das ações governamentais (CINGOLANI, 2013). Nesta linha, para os fins deste artigo, consideram-se duas dimensões de capacidades estatais: recursos organizacionais e estratégias de articulação e gestão que foram subdivididas em seis variáveis conforme se apresenta na próxima seção.

\section{METODOLOGIA}

Este trabalho se apoiou em métodos qualitativos de coleta e análise de dados e recorreu ao método de múltiplos estudos de casos do tipo polares, pois situações extremas têm maior potencial de revelar padrões contrastantes. Foram selecionados os estados de São Paulo e Maranhão e uma política pública nacional, o PETI, considerando sua relevância teórica. O programa possui atributos e características que permitem sua escolha como um caso para a análise em profundidade (EISENHARDT, 1989).

A coleta de dados ocorreu em duas etapas. A primeira, por meio da análise dos documentos que compõem o arcabouço jurídico-normativo do programa, dos atos infraconstitucionais, instruções operacionais e dos três volumes do PETI. Isso permitiu a elaboração de uma narrativa analítica da trajetória do SUAS e do PETI explorando aspectos legais e as alterações normativas que, ao longo do tempo, pudessem implicar o desenvolvimento de capacidades estatais.

A segunda etapa envolveu a realização de entrevistas em profundidade com atores ligados à gestão e técnicos das Secretarias de Desenvolvimento Social de cada estado. Foram conduzidas seis entrevistas no estado de São Paulo e dez entrevistas no Maranhão, sendo os respondentes selecionados de acordo com a sua posição e atribuições que realizam ou realizavam no programa.

Foi observada a presença ou ausência das seis variáveis na estrutura organizacional destes estados e que expressam a existência de capacidades estatais. Apoiado na literatura sobre capacidades estatais, a cada variável foi associada um conjunto de indicadores empiricamente observáveis.

No entanto, a simples existência de tais variáveis no interior do Estado não pode ser interpretada como sinônimo de capacidades (EVANS, RUESCHMEYER e SKOCPOL, 1985), porque tais recursos e competências podem não ser mobilizados na prática ou mesmo transformados em ação (GOMIDE, PEREIRA e MACHADO, 2018). Dessa forma, uma vez identificada a presença da variável, observou-se como ela se organizou em contato com as regras, mecanismos e processos constituídos pelo SUAS e como foi transformada em ação estatal efetiva, possibilitando a criação de capacidades. A seguir são apresentadas as variáveis selecionadas e os indicadores utilizados para sua aferição. 


\section{Quadro 1}

Sistematização das variáveis de identificação de capacidades técnico-administrativa

\begin{tabular}{|c|c|c|c|}
\hline Autor & Variável & Descritivo & Indicador \\
\hline $\begin{array}{l}\text { Skocpol (1985), } \\
\text { Grindle (1996), } \\
\text { Gomide e Pires } \\
\text { (2014) }\end{array}$ & $\begin{array}{l}\text { Qualidade } \\
\text { burocrática }\end{array}$ & $\begin{array}{l}\text { Burocracia qualificada: } \\
\text { presença de burocracia com } \\
\text { características weberianas }\end{array}$ & $\begin{array}{c}\text { 1. Tipo de vínculo e existência } \\
\text { de plano de carreira; } \\
\text { 2. Modelo de recrutamento meritocrático; } \\
\text { 3. Qualificação profissional de acordo com a } \\
\text { Norma Operacional Básica de Recursos Humanos } \\
\text { (NOB)-RH e profissionalização burocrática } \\
\text { (domínio técnico e de gestão). }\end{array}$ \\
\hline $\begin{array}{l}\text { Grindle (1996) } \\
\text { Gomide e Pires } \\
\text { (2014) }\end{array}$ & $\begin{array}{l}\text { Disponibilidade de } \\
\text { recursos financeiros }\end{array}$ & $\begin{array}{l}\text { Capacidade de obtenção de } \\
\text { receita e controle da aplicação } \\
\text { do gasto público }\end{array}$ & $\begin{array}{l}\text { 1. Estabilidade do financiamento da política; } \\
\text { 2. Recursos próprios investidos no programa; } \\
\text { 3. Taxa de execução (proporção do total gasto } \\
\text { pelo programa em relação ao total de recursos } \\
\text { repassados pelo Ministério do Desenvolvimento } \\
\text { Social (MDS) para a execução do programa). }\end{array}$ \\
\hline Grindle (1996) & $\begin{array}{l}\text { Centralidade da } \\
\text { agenda na estrutura } \\
\text { organizacional }\end{array}$ & $\begin{array}{l}\text { Posicionamento institucional } \\
\text { do programa avaliado pela } \\
\text { alocação de recursos humanos, } \\
\text { financeiros e tecnológicos }\end{array}$ & $\begin{array}{l}\text { 1. Qualidade burocrática; } \\
\text { 2. Recursos próprios investidos no programa. }\end{array}$ \\
\hline Mann (1984) & $\begin{array}{l}\text { Alcance territorial e } \\
\text { capilaridade da ação }\end{array}$ & $\begin{array}{l}\text { Capacidade de mobilizar } \\
\text { instituições e aproveitar } \\
\text { burocracias já existentes no } \\
\text { nível local de governo para } \\
\text { implementação das ações }\end{array}$ & $\begin{array}{l}\text { 1. Cobertura territorial das ações; } \\
\text { 2. Reforço burocrático/instituições } \\
\text { envolvidas na implementação. }\end{array}$ \\
\hline $\begin{array}{l}\text { Gomide e Pires } \\
\text { (2014) }\end{array}$ & $\begin{array}{l}\text { Existência e operação } \\
\text { de mecanismos de } \\
\text { Coordenação inter e } \\
\text { intragovernamental }\end{array}$ & $\begin{array}{l}\text { Presença de burocracia com } \\
\text { alta capacidade de articular } \\
\text { interesses e engajar atores para } \\
\text { a implementação das ações }\end{array}$ & $\begin{array}{l}\text { 1. Coalizões articuladas em } \\
\text { torno das metas definidas; } \\
\text { 2. Presença de múltiplas organizações e distintas } \\
\text { burocracias implicadas no arranjo da política; } \\
\text { 3. Existência de instrumentos de coordenação. }\end{array}$ \\
\hline Pedroti (2014) & $\begin{array}{l}\text { Processos de } \\
\text { planejamento, } \\
\text { controle e gestão }\end{array}$ & $\begin{array}{l}\text { Soluções de apoio ao controle } \\
\text { e à gestão desenvolvidas no } \\
\text { escopo do programa }\end{array}$ & $\begin{array}{l}\text { 1. Existência de instrumentos } \\
\text { de gestão (protocolos de gestão, } \\
\text { pactos de aprimoramento etc.). }\end{array}$ \\
\hline
\end{tabular}

Fonte: Elaborado pelos autores.

Cumpre lembrar que o PETI foi instituído em 1996 pelo Governo Federal no Estado do Mato Grosso do Sul e, em 2001, ampliado para os demais estados. O programa compreende: (i) transferência de renda; (ii) oferta de serviços socioeducativos a crianças e adolescentes em situação de trabalho; e (iii) apoio às famílias. Possui abrangência nacional e suas ações são implementadas de forma descentralizada, respeitando as atribuições de cada ente federado. Em 2005, o programa foi integrado ao SUAS, passando a se apoiar nos seus mecanismos de gestão administrativa, financeira e em instâncias de articulação e pactuação. Nesta data, o componente transferência de renda foi integrado ao Programa Bolsa Família (PBF) e, em 2013, o componente socioeducativo foi incorporado ao Serviço de Convivência e Fortalecimento de Vínculos (SCFV).

Em 2014, como resposta ao novo cenário do trabalho infantil apontado pelo Censo 2010 do Instituto Brasileiro de Geografia e Estatística (IBGE), o programa passou por um processo de redesenho que propôs o desenvolvimento de ações estratégicas (AEPETI). Buscava-se potencializar o enfrentamento do trabalho infantil por meio da articulação dos serviços socioassistenciais, das ações intersetoriais e da interlocução com o sistema de justiça, órgãos de controle e sociedade civil. Importa destacar que o redesenho do PETI propôs o aperfeiçoamento do modelo de gestão do programa e se apresentou como um marco factível para analisar como as capacidades estatais foram criadas antes e após o redesenho. 
Dessa maneira, este trabalho observou o processo de construção de capacidades estatais no caso do PETI em dois marcos distintos: desde sua integração ao PBF até o reordenamento do SCFV (2005 a 2013); e do redesenho do PETI a partir de 2014, início das AEPETI, até 2018. Considerando essa construção metodológica com suas variáveis e indicadores, na próxima seção, analisa-se como a ausência ou presença das variáveis selecionadas nos dois períodos esteve associada à construção de capacidades estatais nos dois estados.

\section{Análise das Variáveis Indicativas de Capacidades Estatais}

Autores da vertente estadocêntrica destacam que o principal fundamento da capacidade de ação do estado é a existência de uma burocracia altamente qualificada (EVANS, 1993, 2003; EVANS e RAUSCH, 2014; GEDDES, 1994; SKOCPOL, 1985). Não obstante, a qualidade burocrática, analisada sob a ótica racional weberiana, é consensualmente associada à ampliação da capacidade de ação do Estado para viabilizar seus objetivos. Desta perspectiva, são indicadores de uma burocracia qualificada e exemplos de atributos capazes de construir um quadro de profissionais confiável: o recrutamento meritocrático, a estrutura de carreira de longo prazo e a qualificação técnica (SKOCPOL, 1985). Em alguns estudos, a qualidade burocrática está relacionada à profissionalização de áreas chave do governo, sendo os indicadores a ela associados o domínio técnico e gerencial (GRINDLE, 1996; EVANS, 1995).

No Maranhão, no período anterior ao redesenho do PETI, o quadro de recursos humanos apresentava baixa qualidade burocrática e reduzida capacidade de implementação, exceto no período imediatamente após a integração com o PBF. Embora o recrutamento tenha sido via concurso e os salários fossem compatíveis com as demais pastas do governo, havia baixa qualificação técnica (carreira específica não requer nível superior), inexistia possibilidade de ascensão profissional ou planos de cargos e salários e as promoções dependiam de indicação política. Observou-se o envelhecimento do quadro e número insuficiente de servidores para o desenvolvimento da política de assistência social conforme a NOB/RH.

No momento anterior ao redesenho, a quantidade de servidores disponíveis na Secretaria de Desenvolvimento Social implicou a desaceleração das atividades do programa e seu posterior esvaziamento. Após o redesenho, persistiu a baixa qualidade burocrática, exemplificada pela contratação de equipe temporária e pela inexistência de plano de carreira, tendo sido ampliada, no entanto, a capacidade de implementação da política. A mudança de governo renovou o quadro de gestão da secretaria e alocou em cargos de maior autoridade perfis com trajetória de engajamento ativo na defesa do SUAS e das políticas sociais. Em poucos meses foi firmada uma parceria com a Organização Internacional do Trabalho (OIT) para a realização de diagnósticos sobre a situação do trabalho infantil nos municípios. Ademais, a gestão estadual iniciou a elaboração do Projeto de Fortalecimento e Execução das Ações Estratégicas do PETI no estado, visando capacitar e assessorar as equipes técnicas municipais e realizar campanhas de mobilização e sensibilização.

A análise desse período sugere que outros fatores tiveram consequências sobre as capacidades estatais além da presença de uma burocracia qualificada nos termos aqui sugeridos. Das entrevistas foi possível constatar que o ativismo institucional do alto escalão da secretaria foi decisivo na ampliação da capacidade de implementação do PETI no estado. Com efeito, elementos que não são determinados pelo SUAS também incentivaram a produção de capacidades estatais.

No caso paulista não se constatou uma mudança significativa nos indicadores de qualidade burocrática com o advento do redesenho. Verificou-se a presença de uma burocracia estável e qualificada, ainda que alguns elementos chave alinhados ao modelo weberiano não estivessem presentes, tais como: técnicos de carreiras específicas do SUAS, recrutados por meio de concursos e com formação compatível com a NOB/RH. No entanto, além de os salários serem um dos mais baixos do quadro estadual, não há plano de cargos e carreiras.

A secretaria apresentava alta rotatividade de secretários e clivagens ideológicas em razão da tardia incorporação das carreiras específicas do SUAS no seu quadro administrativo. Porém, a equipe técnica e a coordenação do programa permaneceram as mesmas durante os dois períodos analisados, de sorte que as atividades foram continuadas. Todavia ressalta-se que, diante do constante cenário de instabilidade institucional, a reação da burocracia deste programa garantiu-lhe algum nível de insulamento. Esta realidade implicou crescente ampliação da profissionalização burocrática, com domínio técnico e alta capacidade de gestão, que, por conseguinte, viabilizou a contínua implementação das ações. Neste caso, quando colocados em ação, os atributos presentes na organização burocrática do estado influenciaram a construção de capacidades estatais. 
A literatura destaca, ao lado da qualidade burocrática, a importância da capacidade financeira: autoridade do Estado em obter receita e controlar a aplicação do gasto público. Este componente é destacado por diferentes autores como parâmetro para a mensuração das capacidades técnico-administrativas: maior receita tributária está associada à ampliação do nível esperado de capacidade administrativa (KJAER, HANSEN e THOMSEN, 2002; SKOCPOL, 1985). Baseado em Grindle (1996) e Gomide e Pires (2014), a capacidade financeira foi observada por meio de três indicadores: estabilidade no financiamento da política, recursos próprios investidos no programa e a taxa de execução da política - proporção do total gasto pelo programa em relação ao total de recursos repassados pelo MDS para a sua execução.

No Maranhão, não foram encontradas capacidades financeiras significativas. Apesar da estabilidade adquirida para o financiamento das ações do PETI após o redesenho, não se evidenciou aumento de capacidade técnica associada ao planejamento orçamentário, tampouco houve melhora na geração de receitas próprias ou da taxa de execução da política, em que pese o último ano ter sido mais representativo neste indicador.

O que se observa no caso paulista é diverso. Na primeira década de execução do programa estavam presentes importantes atributos relacionados à capacidade financeira. Em especial, a ausência de recursos exclusivos para o PETI não implicou a subexecução das ações, ao contrário, levou a coordenadoria responsável pelo programa a buscar alternativas para financiá-las. Como na secretaria paulista o programa compartilha a coordenação com o PBF. Muitas ações realizadas no primeiro período foram executadas com recursos do Índice de Gestão Descentralizada do Bolsa Família (IGD-PBF) e verbas do Pró-Jovem, quando havia ações compartilhadas, e por meio de captação de recursos com atores institucionais mobilizados nesta agenda. Dessa forma, mesmo que não houvesse estabilidade do financiamento da política ou recursos próprios investidos, havia capacidade de obter receita e de executar os recursos.

Este cenário foi alterado após o redesenho e se aproximou da realidade maranhense: apesar da estabilidade adquirida para o financiamento das ações do PETI, não houve aumento de capacidades técnicas associado ao planejamento orçamentário e não foi observada melhora na geração de receitas próprias ou de execução da política, com exceção do último ano. A dificuldade de utilizar os recursos federais nos primeiros anos após o redesenho esteve associada a uma política de austeridade do estado e ao consequente cancelamento das atividades previstas para o biênio 2015-16. Divergências de entendimento sobre as possibilidades do programa entre a coordenadoria responsável e o novo secretário da pasta também influíram nesse resultado.

Aqui, mais uma vez, constata-se que a construção de capacidades esteve mais relacionada à inserção do programa na estrutura organizacional da secretaria, protagonista nas instâncias interinstitucionais que tratam do tema, a exemplo do Fórum Paulista de Erradicação do Trabalho Infantil, do que propriamente à política federal de financiamento do programa.

A centralidade da agenda, terceira variável analisada, pode ser compreendida como proxy de capacidades técnicas, em especial quanto à disponibilidade de recursos humanos e financeiros (GRINDLE, 1996). Trata-se do quão central é a agenda de uma determinada política na estrutura organizacional de sua secretaria de origem, como também no quadro mais amplo do governo. A centralidade da agenda favorece a formação de uma burocracia qualificada e a alocação de recursos financeiros para a manutenção de uma dada política (GRINDLE, 1996). No estado maranhense, no período imediatamente após a integração com o PBF, o programa ganhou posição de destaque diante dos demais programas do SUAS em virtude do modelo de cofinanciamento federal aos municípios. O volume de recursos investidos no nível local levou à intensificação das ações da secretaria estadual e contou com quase a totalidade dos técnicos em postos da coordenadoria de origem do programa para a sua implementação. Todavia perdeu centralidade ao final dos anos 2000, na medida em que outros programas do SUAS se consolidaram, como foi o caso do PBF.

Nos anos mais recentes, o que se percebe é um acirramento da disputa (financeira e, em última instância, institucional) entre os programas de governo e aqueles ofertados pelo SUAS. Ao mesmo tempo, não foi observado favorecimento na alocação de recursos humanos ou financeiros para o PETI. É possível afirmar que a centralidade da agenda na estrutura organizacional esteve associada à posição que o programa gozava diante dos demais programas do SUAS, sendo o cofinanciamento federal aos municípios um fator relacionado a esse lugar de vantagem.

De forma bastante diferente do Maranhão, a centralidade da agenda do PETI na estrutura organizacional da Secretaria de São Paulo não esteve relacionada à sua colocação diante dos demais programas do SUAS ou ações governamentais. Não foi identificada qualquer relação entre a centralidade da agenda e a construção de capacidades técnicas no primeiro período analisado. Todavia o segundo período revela que a intervenção do sistema de justiça no controle desta política pública, combinada com a disponibilidade de recursos financeiros advindos do financiamento das AEPETIs pelo governo federal, 
recolocou o programa em um espaço de maior visibilidade dentro da estrutura da secretaria. Em 2016, o Ministério Público Estadual (MPE) abriu um inquérito civil público para apurar conduta do governo do estado quanto à elaboração do PETI.

Ainda que este não seja um instrumento compulsório do PETI, a cobrança veio a reboque de uma ampla mobilização realizada pelo MPE para monitorar a elaboração de planos temáticos municipais. Em seguida, iniciou-se um processo de discussão na secretaria para a elaboração do plano estadual, tendo sido, posteriormente, instituída uma Comissão Intersetorial visando planejar a elaboração e execução do plano. Em 2018, deu-se início à elaboração deste instrumento por meio da realização de audiências públicas. Pode-se afirmar que o ativismo do MPE e a disponibilidade de recursos em conta garantiram a centralidade desta agenda na estrutura organizacional da secretaria. Como decorrência, desencadeou-se a implementação de ações que levaram à ampliação das capacidades técnicas da equipe, a exemplo da articulação e gestão que serão mais bem detalhadas adiante. Contudo a centralidade da agenda no período relatado não influenciou o aumento dos indicadores utilizados tais como recursos humanos ou financeiros - de forma que permitisse observar esta variável.

Outra variável importante relativa às capacidades técnico-administrativas diz respeito à habilidade do Estado de mobilizar instituições e aproveitar burocracias já existentes no nível local de governo. Esta é uma capacidade vinculada à implementação das ações e pode ser considerada como a extensão dos recursos organizacionais. Nessa abordagem, quanto maior o alcance territorial - ou poder infraestrutural nos termos de Mann (1984) -, mais desenvolvidas são, por exemplo, as capacidades estatais de coordenação e gestão. Conforme a literatura (BICHIR, 2016a; COUTINHO, 2014; SOUZA 2017), o alcance territorial pode ser medido pela existência de instituições envolvidas na implementação - o que configura um reforço burocrático ou pela cobertura territorial de suas ações. Ainda que a secretaria maranhense não contasse com uma estrutura organizacional descentralizada, verificou-se uma crescente cobertura territorial das ações do PETI no segundo período analisado. O incremento nas capacidades da coordenadoria responsável pela execução do programa foi um desdobramento das ações realizadas no âmbito do assessoramento in loco de apoio técnico aos municípios. Estas iniciativas aproximaram a gestão estadual dos municípios e fortaleceram a presença municipal no Fórum Estadual de Prevenção e Erradicação do Trabalho Infantil do Maranhão. Essa combinação resultou em maior cobertura territorial da ação da secretaria e permitiu aos órgãos participantes do fórum contar com o mesmo reforço burocrático para a implementação de ações próprias.

No caso paulista, para além da estrutura descentralizada da secretaria estadual, que possui 26 diretorias regionais com equipes próprias para atender a todos os serviços da pasta, a forte institucionalidade da rede de atores externos à assistência engajada na agenda do trabalho infantil contribuiu para a efetividade no alcance territorial das ações. Assim, observou-se que o trabalho de décadas realizado por essa rede nos municípios, igualmente pelos atores do sistema de justiça, favoreceu a institucionalização dessa agenda no nível local e, consequentemente, a adesão deste nível de governo aos programas federalizados.

As duas últimas variáveis estudadas neste trabalho estão associadas a duas capacidades burocráticas: coordenação (articular interesses e engajar atores de forma sinérgica para a implementação de suas ações) e gestão (capacidades processuais-organizacionais) (GOMIDE e PIRES, 2014; PEDROTI, 2014). Ambas podem ser observadas por meio do aparato técnico-administrativo que sustenta uma política, por exemplo: coalizões articuladas em torno de metas definidas, presença de múltiplas organizações e distintas burocracias inseridas no arranjo da política e operação de instrumentos institucionais de apoio à implementação das ações (GOMIDE e PIRES, 2014; PEDROTI, 2014). Portanto instrumentos de coordenação e de gestão são dois recursos organizacionais estratégicos.

Instrumentos coordenativos constituem a própria engenharia institucional dos sistemas de políticas públicas. A necessidade de garantir a implementação nacional de uma política, obedecendo parâmetros mínimos de execução, requer o desenvolvimento de mecanismos de coordenação para promover a regulação e induzir as ações locais em convergência com as diretrizes nacionais (BICHIR, 2014, 2016a; LICIO, 2012). Os instrumentos de gestão podem também ser compreendidos sob o registro coordenativo (PEDROTI, 2014). Nesta linha, instrumento como planos municipais, protocolos de gestão, pactos de aprimoramento, mecanismos de prestação de contas, dentre outros, visam apoiar a implementação da política. A sua elaboração, invariavelmente, envolve a participação de distintas burocracias dos três níveis de governo, de forma que, além de auxiliarem no cumprimento de objetivos de gestão, envolvem também estratégias de coordenação.

O que se constatou no Maranhão, no período após o redesenho, foi a existência de uma estratégia de coordenação vigorosa que visou gerar maior convergência com as ações de outros órgãos de governo. Mesmo que não tenha sido acompanhada do uso de instrumentos coordenativos, resultou na construção de capacidades técnicas. É possível observar que, após o 
redesenho, houve uma completa remodelagem da articulação realizada com os atores do sistema de justiça, bem como com os participantes do fórum estadual. Isto foi possível pela adoção de uma estratégia de coordenação intragoverno apoiada em dois fatores: (i) desenvolvimento de ações próprias articuladas com outros órgãos e (ii) uso do alcance territorial, adquirido nas atividades de assessoramento, para apoiar a implementação de ações de outros órgãos.

Observou-se a formação de um novo padrão de relacionamento entre a coordenadoria responsável pelo programa e os atores centrais desta agenda, a exemplo da Superintendência Regional do Trabalho (SRT), das secretarias estaduais de saúde, de direitos humanos, MP estadual, dentre outros. Como resultado, foram ampliadas as capacidades da burocracia da secretaria de articular diferentes interesses em torno do projeto estadual, como também houve o incremento do domínio técnico e sua profissionalização. Para além disto, a estratégia coordenativa implementada pela secretaria forjou a capacidade de alcance territorial de outros órgãos do governo. Em relação a esta última operação, o que se percebe é um trade-off entre a secretaria, que ganhou facilidade na mobilização de sua agenda, e os órgãos participantes do fórum, que adquiriram capilaridade de ação.

Diferentemente do caso maranhense, as atividades coordenativas realizadas pela secretaria paulista não resultaram em um novo padrão de relacionamento entre esta burocracia e os demais atores envolvidos nesta agenda. A estratégia de coordenação adotada pela secretaria esteve mais a serviço da manutenção de um padrão de relacionamento interinstitucional já constituído nos anos anteriores àqueles analisados nesta pesquisa. Registre-se que o protagonismo da coordenadoria paulista na agenda do trabalho infantil data do surgimento do Fórum Paulista (1999), seja na realização de projetos em conjunto com essa instância, seja na oferta de ações protetivas em complemento à atuação do sistema de justiça antes de 2005.

De forma muito próxima à configuração nacional, esta rede combina o protagonismo dos órgãos do sistema de justiça com diferentes atores institucionais envolvidos na promoção de políticas protetivas. Com efeito, este quadro institucional tem garantido resultados positivos no desencadeamento de ações realizadas pelo executivo paulista. Se internamente as relações estabelecidas entre a coordenadoria do programa e os atores do fórum serviram para reforçar os interesses da equipe em momentos críticos de mudança, externamente foram fundamentais para garantir a amplitude das ações do PETI no estado.

No período analisado, não é possível afirmar que as atividades coordenativas levaram à ampliação das capacidades técnicas. O que se observa é um incremento gradual destas capacidades com a implementação das rodadas bianuais de oficinas regionalizadas para técnicos municipais e das audiências públicas para a elaboração do plano estadual. Nos dois casos, foram fortalecidas as capacidades de articular diferentes atores e negociar interesses comuns para a oferta do currículo formativo e a construção de consensos em torno dos problemas diagnosticados. Mesmo existindo uma estratégia clara e permanente de coordenação horizontal, não foi observado o uso de instrumentos de coordenação.

As soluções propostas no escopo do programa maranhense, voltadas a apoiar planejamento, controle e gestão, indicavam a existência de capacidades técnicas. Após o redesenho, as capacidades estatais foram ampliadas por meio do emprego de instrumentos de gestão. Identificou-se o emprego de dois destes instrumentos associados à função coordenativa e à ampliação das capacidades técnicas. A elaboração dos Planos de Ação Municipais garantiu o enforcement às normativas do MDS, e o assessoramento in loco das ações foi o instrumento para registrar as providências a serem tomadas pela equipe municipal assumidas como compromissos pelo gestor da pasta. Este processo foi bem sucedido ao criar uma rotina transparente e, na maioria das vezes, cooperativa entre os dois níveis de governo. Ambos os instrumentos fortaleceram a capacidade de enforcement da secretaria maranhense, garantiram a cooperação dos municípios ao projeto estadual e ampliaram a capacidade do estado de implementar a política.

No caso paulista, no período analisado, os processos de planejamento e gestão também estiveram associados ao incremento das capacidades técnicas. O planejamento das ações seguiu os ritos de gestão do SUAS, com a elaboração quadrienal do Plano Estadual de Assistência Social (PEAS) e anual de planos de ação com base nas diretrizes do MDS e do PEAS, e sua submissão à aprovação do Conselho Estadual. Além dos ritos que fazem parte da institucionalidade do SUAS, a equipe de coordenação responsável pelo programa organizou uma rotina administrativa bastante engajada. A coordenação da equipe esteve até o último governo nas mãos de uma gestora sintonizada com as exigências da nova cultura institucional demandada pelo SUAS. Sua atuação buscou promover a necessária base conceitual para viabilizar as ações dentro de seus princípios políticos e programáticos.

Tal compromisso ocasionou várias rotinas administrativas à equipe e apoiou a continuidade das ações do PETI, mesmo diante das mudanças vivenciadas pelo programa ou do cenário de incerteza característico desta secretaria. Ao longo dos anos, 
a equipe aprimorou sua capacidade de interpretação da legislação e atos infralegais, bem como sua habilidade para absorver e desenvolver informações sobre conteúdos e problemas no tema. Desde o marco do redesenho, entretanto, foi observada uma ampliação mais substancial das capacidades técnicas, em especial por meio das atividades desempenhadas em torno do marco regulatório inerente à elaboração do Plano Estadual. Estas regras requerem, por exemplo, observar o devido processo licitatório, a coordenação da Comissão Estadual, a realização das audiências públicas e a elaboração do plano. Estas medidas invariavelmente exigiram da equipe um aprimoramento de suas capacidades de gestão.

\section{Resultados dos Casos Comparados}

Esta pesquisa investigou como o SUAS afeta as capacidades estatais dos governos estaduais na implementação de política de assistência social. Sistemas de políticas públicas preveem certa homogeneidade na implementação de políticas em escala nacional: suas regras, mecanismos e processos são iguais para todos os estados (ARRETCHE, 1996; BICHIR, 2011, 2016a; LICIO, 2012). Porém a constatação de que as capacidades dos governos estaduais no âmbito do SUAS são heterogêneas relativiza esta perspectiva (PEREIRA, 2016; SILVA, 2015; SOUZA, 2018).

Se as características institucionais do SUAS são insuficientes para explicar a elevada diversidade nas capacidades estatais dos governos estaduais, existem outros fatores que condicionam o desenvolvimento das capacidades desses governos de implementar e gerir a política de assistência social. Isto posto, a pesquisa revelou quais foram as variáveis presentes nos governos estaduais que, combinadas com o quadro normativo e a engenharia institucional do SUAS, possibilitaram ou constrangeram a criação de capacidades estatais.

Em primeiro lugar, esta pesquisa constatou que, como anunciado, o desenho institucional da política não é, inicialmente, produtor de capacidades estatais. Nos casos estudados, a construção dessas capacidades dependeu da presença de variáveis no interior do estado e, notadamente, da forma como estas interagiram com o quadro normativo da política. Verificou-se, sobretudo, que certas condições contextuais exógenas ao SUAS (ativismo institucional, posição da política na estrutura organizacional e em relação ao projeto de governo, existência prévia de instâncias de coordenação e atores externos engajados na política) também condicionaram a produção de capacidades no âmbito do PETI.

No caso maranhense, as condições que tornaram possível a construção de capacidades estatais foram: (i) o ativismo institucional, (ii) a posição da política em relação ao projeto de governo mais amplo, (iii) a existência prévia de instâncias de coordenação horizontal e (v) o emprego de instrumentos de coordenação intergovernamental.

Observou-se que as capacidades técnicas foram constituídas independentemente da existência de uma burocracia qualificada, conforme tratado neste trabalho. No entanto, a existência do ativismo institucional no alto escalão da secretaria foi determinante para a construção de capacidades. Em um dado momento, o programa ganhou posição de destaque dentre as demais iniciativas do SUAS em virtude do cofinanciamento federal aos municípios, o que gerou maior disponibilidade de recursos humanos e ampliação da capacidade da secretaria para implementar o programa. Todavia o acirramento da disputa entre programas do SUAS e aqueles próprios de governo constrangeu a construção de capacidades. Assim, a posição do programa na agenda do governo operou como reguladora no desenvolvimento de capacidades.

Outro fator determinante no incremento de capacidades técnicas diz respeito à intensidade e à amplitude da coordenação horizontal adotada pela secretaria maranhense, viabilizada pela existência de instâncias de gestão de políticas correlatas à agenda do trabalho infantil. A coordenação intergovernamental também foi vital para produzir capacidades, lembrando que no Maranhão a escolha do governo estadual - assessoramento in loco para implementar a política - promoveu o necessário consenso operacional e ampliou o alcance territorial de sua ação. A adoção de instrumentos institucionais com qualidade de enforcement também se mostrou como condição importante na promoção de capacidades.

No caso do governo paulista, as condições inerentes à construção de capacidades estatais foram diversas: (i) a instabilidade do ambiente institucional, (ii) a inserção da política na estrutura organizacional, (iii) a institucionalidade da política fora da assistência social, e (iv) o ativismo dos atores do sistema de justiça.

A presença de atributos burocráticos weberianos não foi o único determinante na construção de capacidades, uma vez que contingências do quadro institucional da secretaria contribuíram para dotar a equipe de certo "insulamento" favorável ao incremento das capacidades estatais. A inserção do programa na estrutura organizacional foi um fator associado à existência de capacidade financeira. Mesmo que não houvesse estabilidade do financiamento da política ou recursos próprios investidos 
no primeiro período analisado, o programa esteve alocado em uma coordenadoria estratégica. Assim, à época, figurou ao lado de políticas de maior peso no SUAS, o que possibilitou o planejamento e a execução de recursos de forma conjunta. A construção da capacidade financeira esteve mais relacionada à inserção do programa na estrutura organizacional da secretaria do que propriamente à normativa federal de financiamento do programa.

A formação de capacidades estatais no programa paulista também esteve intrinsecamente relacionada à existência de uma rede interinstitucional que concentra burocracias estaduais de maior peso e não diretamente vinculada à assistência social. A origem da agenda do trabalho infantil possibilitou a constituição de um quadro institucional mais calibrado e preponderante na formulação do que atualmente é o sistema de garantia dos direitos da criança e do adolescente, tendo como protagonista diversos atores do sistema de justiça. Há pelo menos duas implicações positivas desta configuração para a conformação de capacidades: a garantia de estabilidade das ações diante das adversidades do ambiente institucional da secretaria e a atuação da rede como reguladora do pacto federativo quando os incentivos federais se mostraram insuficientes para induzir a implementação das AEPETIs, como ocorreu na intervenção do MPE em 2016.

Ainda à luz dos resultados, é possível afirmar que as capacidades estatais possuem um caráter provisório. Sua constituição depende de uma configuração que não é determinada pelo quadro normativo da política per se, o que as faz presentes em determinados momentos, mas não em outros. $O$ desenho institucional de uma política pode atuar como um impulsionador de capacidades, mas não necessariamente garante a sua permanência, haja vista que condições internas aos governos são oscilantes. Portanto, analiticamente, é preciso ir além da normativa da política e considerar sua implementação para observar a permanência das capacidades estatais, tal como realizado nessa pesquisa.

Como observado, no Maranhão, após a integração com o PBF, o PETI assumiu destaque diante dos demais programas do SUAS, o que ampliou sua capacidade de implementar a política. Após anos sem incrementar as capacidades no escopo do programa, houve notável incremento de recursos técnicos com a implementação das AEPETIs, pois variáveis de estoque no interior do estado foram mobilizadas ampliando as capacidades. Observou-se, neste período, maior capacidade financeira, medida pela taxa de execução, de coordenação inter e intragovernamental e de gestão, com destaque para a capacidade de enforcement inexistente anteriormente. Em São Paulo, as capacidades oscilaram menos, mas também verificou-se seu caráter transitório: capacidades financeiras existentes no primeiro período não se mantiveram posteriormente, a perda da autonomia dos tecnocratas e da centralidade no processo decisório, ocorrida na troca da última gestão, foi uma barreira à mobilização de capacidades técnicas antes presentes, e capacidades de gestão foram reforçadas desde a elaboração do Plano Estadual.

\section{CONCLUSÕES}

Esta pesquisa buscou revisar as interpretações sobre o papel dos governos estaduais no SUAS. Como visto, a instituição do SUAS alterou expressivamente o cenário de fragilidade característico na trajetória da assistência social. O SUAS delineou os conteúdos dessa política organizando a provisão de seguranças sociais e a defesa de direitos no âmbito da assistência social. Foram adotados mecanismos democráticos para a tomada de decisão, uma nova engenharia operacional para induzir a adesão nos níveis subnacionais, em linha com novos padrões técnicos de implementação da política. Contudo, como aponta a literatura, o SUAS delegou aos entes estaduais um papel centrado em atividades não finalísticas e pouco atrativas do ponto de vista do cálculo eleitoral. Assim, não estabeleceu um sistema de incentivo suficientemente indutor de ações neste nível de governo (BICHIR, 2011, 2016b; FRANZESE, 2010; SILVA, 2015; SOUZA, 2018).

Observou-se nos dois estudos de caso que o arranjo institucional no âmbito do PETI, em última instância, informou sobre o papel que o governo do estado pode assumir. Em outras palavras, as condições estruturais, institucionais e políticas inerentes a cada governo, quando em contato com o conjunto normativo da política federalizada, podem gerar várias operações implantadas por governos estaduais que permitem especificar seus papéis. O governo maranhense ganhou maior relevância indutora e assumiu centralidade na coordenação e acompanhamento dos municípios, de forma a incidir sobre a qualidade e adequabilidade das ações locais às normativas federais. No caso paulista, a ênfase esteve na adoção de uma política regionalizada, orientada para coordenar, regular e estruturar ações de alcance estadual apoiadas na capacidade burocrática instalada neste nível. Com efeito, o papel assumido pelos estados como coadjuvante da municipalização ou facilitador de uma política regionalizada está relacionado às capacidades criadas para melhor implementar uma política. 
Se a construção de capacidades depende de uma configuração que não é previamente e exclusivamente determinada pela normativa de uma política, é possível inferir que o papel do governo estadual em uma política também depende de tais condições. Nesta linha, importam fatores como o ativismo institucional, a posição da política na estrutura organizacional e em relação ao projeto de governo, a existência prévia de instâncias de coordenação, a institucionalidade da rede de atores externos engajados na política, dentre outras condições. Isto indica que o conjunto normativo que determina o papel do estado é somente um ponto de partida: a relevância dos estados no SUAS mudará de acordo com o arranjo que se conforma na implementação de cada política. Conclui-se, no âmbito da política analisada, que o papel do estado não é tácito, mas sim criado de acordo com as condições inerentes a cada governo, assim como são suas capacidades estatais. Esta pesquisa abre campo para investigar quais capacidades estatais são mais decisivas em trazer os governos estaduais "para dentro" do sistema. 


\section{REFERÊNCIAS}

ABRUCIO, F. L.; FRANZESE, C.; SANO, H. Trajetória recente da cooperação e coordenação no federalismo brasileiro: avanços e desafios. República, Democracia e Desenvolvimento, contribuições ao Estado brasileiro contemporâneo, v. 10, p. 129-163, 2013.

ARRETCHE, M. T. S. O mito da descentralização: maior democratização e eficiência das políticas públicas. Revista brasileira de ciências sociais, v. 11, n. 31, p. 44-66, 1996.

ARRETCHE, M. T. S. Políticas sociais no Brasil: descentralização em um Estado federativo. Revista Brasileira de Ciências Sociais, v. 14, n. 40, p. 111-141, 1999.

$\mathrm{BICHIR,} \mathrm{R.} \mathrm{Mecanismos} \mathrm{federais} \mathrm{de} \mathrm{coordenação} \mathrm{de} \mathrm{políticas} \mathrm{sociais}$ e capacidades institucionais locais: o caso do Programa Bolsa Família. 2011. Tese (Doutorado) - Programa de Pós-Graduação em Sociologia e Ciência Política, Instituto de Estudos Sociais e Políticos, Universidade do Estado do Rio de Janeiro, Rio de Janeiro, 2011.

BICHIR, R. Novas Agendas, Novos Desafios: Reflexões sobre as relações entre transferência de renda e assistência social no Brasil. Novos Estudos, n. 104, p. 111, 2016a.

BICHIR, R. Novos instrumentos de coordenação federativa: reflexões a partir do Programa Bolsa Família. Revista Brasileira de Políticas Públicas e Internacionais, v. 1, n. 1, p. 49-78, 2016b.

BICHIR, R. Os mecanismos de coordenação federal do Programa Bolsa Família. Brasília, DF: MDS, Sagi, 2014.

BOWMAN, A. O. M.; KEARNEY, R. C. Dimensions of state government capability. Western Political Quarterly, v. 41, n. 2, p. 341-362, 1988.

CINGOLANI, L. The State of State Capacity: a review of concepts, evidence and measures. United Nations University - Maastricht Economic and Social Research Institute on Innovation and Technology (MERIT), 2013. (MERIT Working Papers, n. 2013-053). Disponível em: <https://www.merit.unu.edu/publications/working-papers/ abstract/?id=5017>. Acesso em: 14 jul. 2020.

COUTINHO, D. R. Entre eficiência e legitimidade: O Bolsa Família no desafio de consolidação do SUAS. In: GOMIDE, A. A.; PIRES, R. R. C. (Eds.). Capacidades Estatais e Democracia: Arranjos institucionais de políticas públicas. Brasília, DF: IPEA, 2014. p. 267-293.

EISENHARDT, K. M. Building theories from case study research. Academy of management review, v. 14, n. 4, p. 532-550, 1989.

EVANS, P. O Estado como problema e solução. Lua Nova: Revista de Cultura e Política, São Paulo, n. 28, p. 107-156, 1993.

EVANS, P. El hibridismo como estrategia administrativa: combinando la capacidad burocrática con las señales de mercado y la democracia deliberativa. Reforma y Democracia, n. 25, p. 7-32, 2003.

EVANS, P. B. Embedded autonomy: States and industrial transformation. Nova Jersey: Princeton University Press, 1995.

EVANS, P. B.; RAUSCH, J. E. Burocracia e crescimento: uma análise internacional dos efeitos das estruturas do Estado "weberiano" sobre o crescimento econômico. Revista do Serviço Público, v. 65, n. 4, 2014, p. 407-437.

EVANS, P. B.; RUESCHMEYER, D.; SKOCPOL, T. On the road toward a more adequate understanding of the State. In: EVANS, P. B.;
RUESCHMEYER, D.; SKOCPOL, T. (Orgs.). Bringing the state back in. Cambridge: Cambridge University Press, 1985. p. 346-366.

FARIAS C. A. P. (Orgs.). Federalismo e políticas públicas no Brasil. Rio de Janeiro: Editora Fiocruz, 2013.

FRANZESE, C. Federalismo cooperativo no Brasil: da Constituição de 1988 aos sistemas de políticas públicas. 2010. Tese (Doutorado em Administração Pública e Governo) - Escola de Administração de Empresas de São Paulo, Fundação Getulio Vargas, São Paulo, 2010.

FRANZESE, C.; ABRUCIO, F. L. Efeitos recíprocos entre federalismo e políticas públicas no Brasil: os casos dos sistemas de saúde, de assistência social e de educação. In: HOCMAN, G.; GEDDES, B. (Eds.). Politician's Dilemma: building state capacity in Latin America. Los Angeles: University of California Press, 1994.

GOMIDE, A. D. A; PEREIRA, A. K.; MACHADO R. A. Burocracia e capacidade estatal na pesquisa brasileira. In: PIRES, R.; LOTTA, G.; OLIVEIRA, E. (Orgs.). Burocracia e políticas públicas no Brasil: interseções analíticas. Brasília, DF: IPEA: Enap, 2018. p. 85-104.

GOMIDE, A. D. A.; PIRES, R. Capacidades estatais e democracia: a abordagem dos arranjos institucionais para análise de políticas públicas. Brasília, DF: IPEA, 2014.

GRIN, E. J. Notas sobre a construção e a aplicação do conceito de capacidades estatais. Revista Teoria \& Sociedade, v. 20, n. 1, p. 149-178, 2012.

GRIN, E. J. Rotas federativas para a promoção de capacidades estatais municipais: uma análise da experiência brasileira. 2016. Tese (Doutorado em Administração Pública e Governo) - Escola de Administração de Empresas de São Paulo, Fundação Getulio Vargas, São Paulo, 2016.

GRIN, E. J.; ABRUCIO, F. L. Quando nem todas as rotas de cooperação intergovernamental levam ao mesmo caminho: arranjos federativos no Brasil para promover capacidades estatais municipais. Revista do Serviço Público, v. 69, n. esp., p. 85-122, 2018.

GRINDLE, M. S. Challenging the State: crisis and innovation in Latin America and Africa. Cambridge, Inglaterra: Cambridge University Press, 1996.

GRINDLE, M. S. (Ed.). Getting Good Government: capacity building in the public sector of developing countries. Massachussetts: Harvard University Press, 1997.

KJAER, M.; HANSEN, O. H.; THOMSEN, J. P. F. Conceptualizing state capacity: Testing the Validity of Tax Compliance as a Measure of State Capacity. Gothenburg: University of Gothenburg, 2002. (Democracy, the State, and Administrative Reforms Research Report, n. 6).

LICIO, E. C. Para além da recentralização: os caminhos da coordenação federativa do Programa Bolsa Família (2003-2010). 2012. Tese (Doutorado em Política Social). Universidade de Brasília, Brasília, DF, 2012.

MANN, M. The autonomous power of the state: its origins, mechanisms and results. European Journal of Sociology/Archives européennes de sociologie, v. 25, n. 2, p. 185-213, 1984. 
OLSEN, J. P. Maybe It Is Time to Rediscover Bureaucracy. Journal of Public Administration Research and Theory, v. 16, n. 1, p. 1-24, 2006.

PEDROTI, P. M. Desenvolvimento e inclusão social: o caso do arranjo político institucional do Programa Nacional de Produção e Uso do Biodiesel. In: GOMIDE, A, A.; PIRES, R. R. C. (Eds.). Capacidades estatais e democracia: arranjos institucionais de políticas públicas. Brasília, DF: IPEA, 2014. p. 213-236.

PEREIRA, J. M. O papel reservado aos estados na gestão descentralizada do Programa Bolsa Família: desafios e oportunidades. 2016. Tese (Doutorado) - Universidade Federal do Rio de Janeiro, Rio de Janeiro, 2016.

SIKKINK, K. Ideas and institutions: Developmentism in Brazil and Argentina. Ithaca and London: Cornell University Press, 1991.

SIKKINK, K.; WOLFSON, L. Las capacidades y la autonomia del Estado en Brasil y la Argentina: un enfoque neoinstitucionalista. Desarrollo Económico, v. 32, n. 128, 1993. p. 543-574.

SILVA, A. L. N. D. Os estados no Suas: uma análise da capacidade institucional dos governos estaduais na assistência social. 2015.
Dissertação (Mestrado) - Universidade Federal do Rio Grande do Norte, Natal, 2015

SKOCPOL, T. Bringing the state back in: strategies of analysis in current research. In: EVANS, P. B; RUESCHMEYER, D.; SKOCPOL, T. (Orgs.). Bringing the state back in. Cambridge: Cambridge University Press, 1985. p. 3-38.

SKOCPOL, T.; FINEGOLD, K. State capacity and economic intervention in the early New Deal. Political Science Quarterly, v. 97, n. 2, p. $255-$ 278,1982

SKOWRONEK, S. Building a new American state. Cambridge: Cambridge University Press, 1984.

SOUZA, C. Federalismo e capacidades estatais: o papel do estadomembro na política de assistência social. In: PIRES, R.; LOTTA, G.; OLIVEIRA, E. (Orgs.). Burocracia e políticas públicas no Brasil: interseções analíticas. Brasília: IPEA: Enap, 2018. p. 289-297.

SOUZA, C. Modernização do Estado e construção de capacidade burocrática para a implementação de políticas federalizadas. Revista de Administração Pública, Rio de Janeiro, v. 51, n. 1, p. 27-45, 2017.

Fabiana Tock

ORCID: https://orcid.org/0000-0002-1175-7469

Mestre em Administração Pública e Governo pela Escola de Administração de Empresas de São Paulo da Fundação Getulio Vargas (FGV EAESP); Coordenadora do programa Cidades e Desenvolvimento Urbano na Fundação Tide Setubal, São Paulo - SP, Brasil. E-mail: fabiana.tock@gmail.com

Eduardo José Grin

ORCID: https://orcid.org/0000-0002-0488-8487

Doutor em Administração Pública e Governo pela Escola de Administração de Empresas de São Paulo da Fundação Getulio Vargas (FGV EAESP); Professor do Departamento de Gestão Pública da Escola de Administração de Empresas de São Paulo da Fundação Getulio Vargas (FGV EAESP), São Paulo - SP, Brasil. E-mail: eduardo.grin@ fgv.br

Lauro Gonzalez

ORCID: https://orcid.org/0000-0001-9316-6525

Doutor em Economia de Empresas pela Escola de Economia de São Paulo (EESP-FGV); Coordenador do Centro de Estudos de Microfinanças e Inclusão Financeira da Fundação Getulio Vargas (FGVcemif); Professor da Escola de Administração de Empresas de São Paulo na Fundação Getulio Vargas (FGV EAESP), São Paulo - SP, Brasil. E-mail: lauro.gonzalez@fgv.br 